\title{
Large Dentigerous Cyst associated with Supernumerary Canine with Unilateral Nasal Obstruction: An Unusual Case
}

\author{
${ }^{1}$ Abhinandan B hattacharjee, ${ }^{2}$ Adity Chakraborty, ${ }^{3}$ Aakanksha Rathor, ${ }^{4}$ Bandana Talukdar
}

\begin{abstract}
Dentigerous cyst is the most frequent developmental odontogenic cysts. It forms in relation to unerupted teeth, decidous teeth or supernumerary tooth as seen in our case. It is common in younger individuals in lower jaw involving mostly the third molar region. Here, we report a case of 25 years old female with a large dentigerous cyst of right maxilla who presented with complete unilateral nasal obstruction. Radiologically, a supernumerary tooth was seen located superiorly in the medial wall of the maxillary antrum. The cyst was surgically removed through a gingivobuccal sulcus incision. Although, Weber Fergusson incision is generally required for removal of large cysts, sublabial or Caldwell-Luc approach is equally useful for large cyst removal and is also more cosmetically acceptable.
\end{abstract}

Keywords: Dentigerous cyst, Nasal obstruction, Supernumerary tooth.

How to cite this article: Bhattacharjee A, Chakraborty A, Rathor A, Talukdar B. Large Dentigerous Cyst associated with Supernumerary Canine with Unilateral Nasal Obstruction: An Unusual Case. World J Dent 2015;6(2):104-107.

\section{Source of support $\mathrm{Nil}$}

Conflict of interest: None

\section{INTRODUCTION}

Dentigerous cyst comprises of $15 \%$ of all jaw cysts and is the most frequent developmental odontogenic cysts. ${ }^{1}$ They form in relation to unerupted tooth or around crowns of developing tooth from remains of enamel organ, i.e. the odontogenic epithelium. The cyst attaches around the neck of the tooth near the amelocemental junction. A total of $2.6 \%$ of patients with unerupted teeth have dentigerous cysts. Dentigerous cysts are uncommon in the first decade of life and are more often found between the ages of 20 and 50. It is common in the lower jaw, the teeth most frequently affected are the

\footnotetext{
${ }^{1}$ Assistant Professor, ${ }^{2} \mathrm{R}$ egistrar, ${ }^{3,4}$ Postgraduate Trainee

${ }^{1,3,4}$ Department of E NT, Silchar Medical College, Silchar, Assam India

${ }^{2}$ Department of Oncology, Silchar Medical College, Silchar Assam, India
}

Corresponding Author: Abhinandan Bhattacharjee, Assistant Professor, Department of ENT, House No. 23/23, Green Park Silchar, Assam, India, Phone: 91-3842-242784, e-mail: dr_abhinan dan1@ rediffmail.com mandibular third molars and maxillary canines followed by mandibular premolars and maxillary third molars. They vary greatly in size, from less than $2 \mathrm{~cm}$ in diameter to massive expansion of the jaws. Clinical presentations ranging from asympomatic to epiphora, sinus headache and gross facial deformity. Supernumerary teeth are often associated with follicular cysts, which lead to significant bone destruction and root resorption of the permanent incisors. $^{2}$

\section{CASE REPORT}

A female of 25 years of age presented with a swelling of right cheek and upper alveolus for 1 year. The swelling was painless and was gradually increasing in size. Her chief presenting complaint was complete nasal obstruction on the right side. She had no facial pain, fever, nasal discharge, eye or dental problem. The fullness in right upper alveolus and sublabial sulcus caused her difficulty in chewing and feeding.

\section{Examination}

A $5 \times 6 \mathrm{~cm}$ (approximate) bony hard nontender swelling with ill-defined margins was felt on the anteromedial and superior aspect of right maxilla. Nasal patency was grossly reduced on the affected side. Nasal endoscopy showed complete obstruction with lateral wall of nose being pushed medially touching the septum and floor of the nose pushed upwards. In oral examination, there was a bony swelling in the gingivobuccal sulcus and palate. Dentition and condition of adjacent tooth was normal with no loosening or loss of tooth. Eye, general and systemic examination revealed no abnormality.

\section{Investigation}

Skiagram of the paranasal sinuses (occipitomental view) was advised which showed a radiolucent shadow in right maxilla with gross medial bulging of the lateral wall of nose. Interestingly, a radiopaque shadow suggesting a tooth in the superomedial part of right maxillary antrum was noted inside the cyst (Fig. 1). Another radiopaque shadow seen over the left side of nose was an artefact (nose ornament) which was not removed because of the patient's religious belief. Routine hematological investigations were done for preoperative evaluation which were within normal limits. 


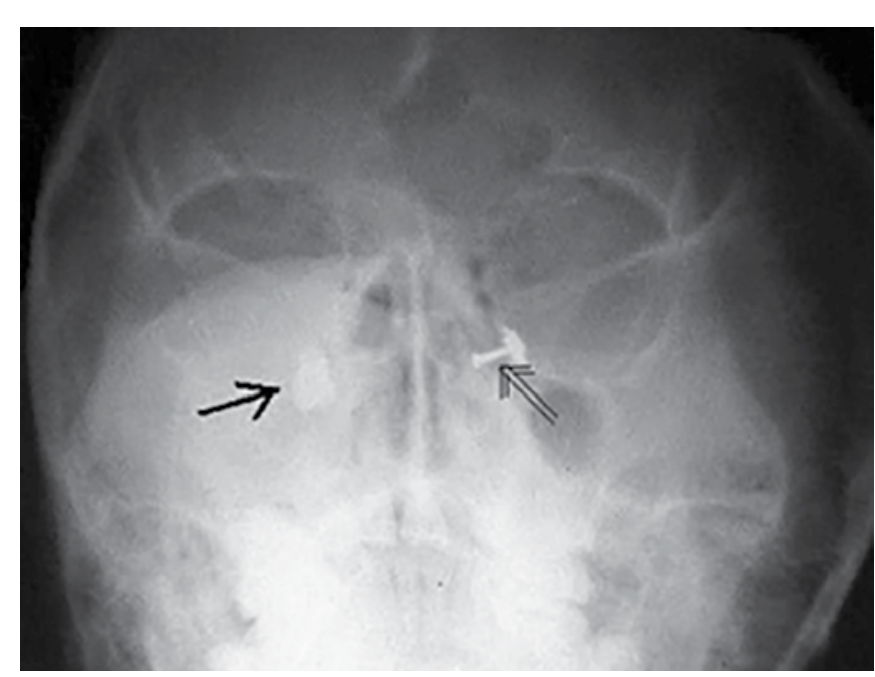

Fig. 1: X-ray of paranasal sinuses showing dentigerous cyst with ectopic supernumerary tooth (bold arrow). Double arrow showing artifact (nose ornament)

\section{TREATMENT}

Under general anesthesia, an incision around the gingival margins of the teeth was made starting from the roots of first incisor extending to the first molar tooth. This method would allow suturing over sound bone and was preferred. The alveolar mucosa was freed from the underlying thinned out alveolar bone and retracted to expose the cyst. The cyst was bluntly dissected out in toto from the anterior, superior and medial antral walls. The antral walls was found ballooned out due to the expanding cyst (Fig. 2). Some parts of anterior wall and whole of the medial wall of maxillary sinus was grossly thinned out due to pressure necrosis and was firmly adhered to the cyst wall. On removal of the cyst, there was a large defect involving the lateral wall of nose and anterolateral wall of maxilla resulting in a direct communication with the floor of the nose and maxillary antrum. The defect did not require any reconstruction.

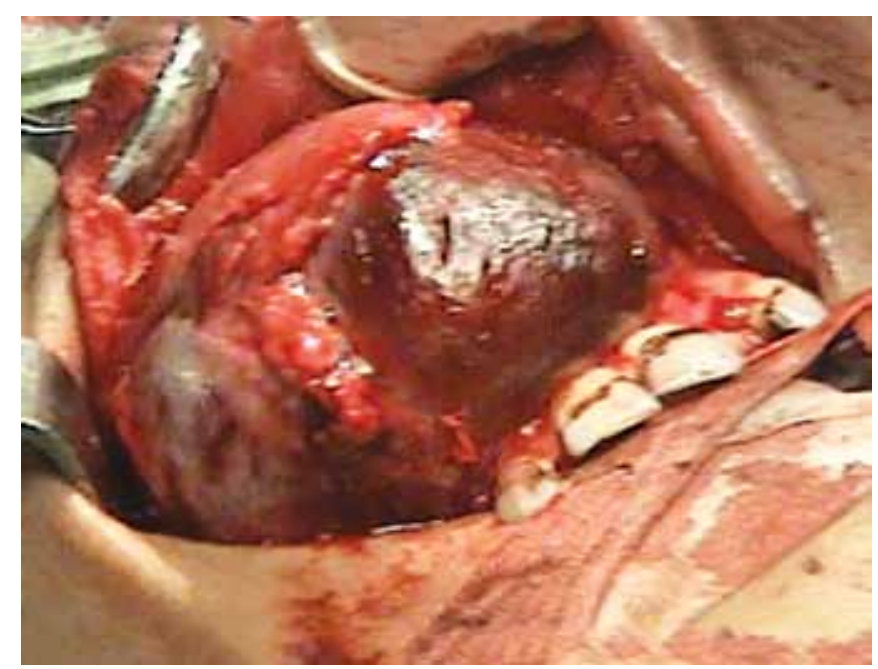

Fig. 2: Intraoperative photograph showing extent of cyst and thinning out and erosion of antral walls
The gross specimen consisted of a globular expanded soft tissue measuring $6 \times 6 \times 3 \mathrm{~cm}$. An impacted supernumerary canine tooth was found inside the cyst situated in the upper aspect of anterolateral wall of the maxilla (Fig. 3). The cyst contained brownish fluid and mucoid material. The cyst was seen attached to the neck of the tooth, and the crown lied within the cyst.

Before closure, the antrum was packed with antibiotic impregnated ribbon gauge for hemostasis. The patient was given parenteral antibiotics till the pack was completely removed on the second postoperative day. At followedup during first week then at 1 month, patient had nasal complaints, the adjacent tooth was vital and fibrotic reactive tissue was seen to gradually reform the maxillary antrum.

\section{DISCUSSION}

Dentigerous cyst is a developmental odontogenic cyst which develops from the reduced enamel epithelium in an impacted tooth and is usually associated with deciduous $^{1,3}$ or unerupted permanent tooth. Supernumerary teeth or hyperdontia are defined as an excess number of teeth when compared to the normal dental formula. The prevalence ranges between 0.3 and $0.8 \%$ in the primary dentition and 0.1 to $3.8 \%$ in the permanent dentition. ${ }^{5-7}$

Dentigerous cysts of the maxillary sinus are most commonly associated with maxillary third molars ${ }^{8,9}$ and is rarely associated with supernumerary teeth..$^{10,22}$ Only two studies have shown its association with impacted anterior supernumerary maxillary tooth. ${ }^{15,22}$ We report an unusual case of ectopic supernumerary canine tooth in a rare location outside the dental area, located superiorly in the medial wall of right maxillary antrum and presented with complete unilateral nasal obstruction. The only other case report of supernumerary canine in maxilla was reported by Most and Roy (1982).

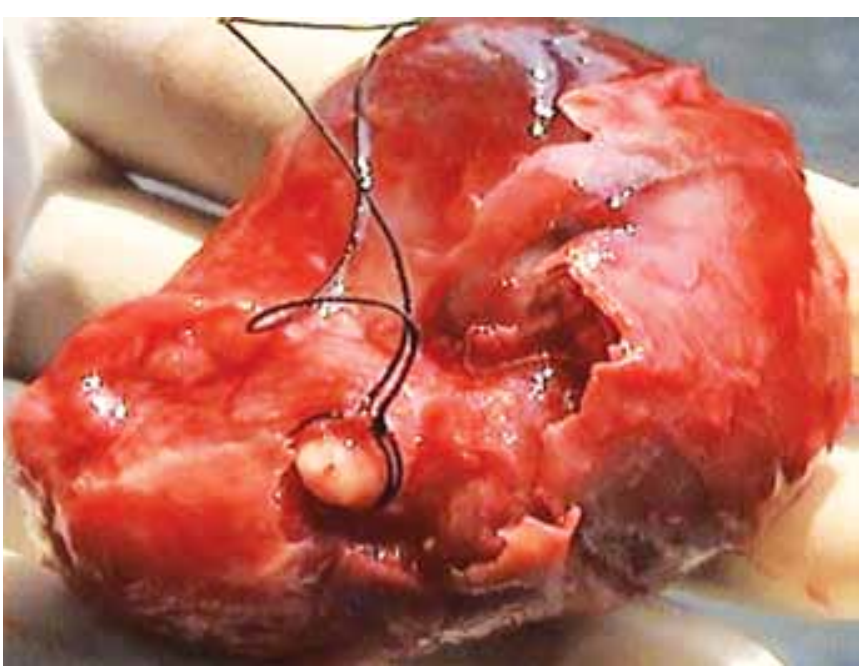

Fig. 3: Specimen of dentigerous cyst containing the supernumerary canine tooth 
Dentigerous cyst when involves the upper jaw, extensively involves the maxillary antrum and surrounding bone due to its expanding nature and causes varied presentation and significant morbidity. ${ }^{9}$ Atlas et al reported epiphora as a presenting feature produced due to a large maxillary cyst involving the whole sinus. ${ }^{12}$ Other reported presenting clinical features are facial cellulitis or pyocele, ${ }^{4}$ recurrent sinusitis, ${ }^{18}$ headache with facial pain and a slow growing painless swelling on the upper lip region ${ }^{19}$ and paresthesia on the affected side. ${ }^{21}$

Our case is perhaps the first to be reported with complete unilateral nasal obstruction with moderate external facial deformity. It was the expanding cyst that pushed the lateral nasal wall and floor of the nose. Dentigerous cyst attains large size with resorption of root of adjacent tooth ${ }^{11}$ and can reach up to the base of the skull ${ }^{4}$ and into the orbital rim and floor. In our case, the lesion was extensive enough to involve almost the entire maxillary antrum but there was no resorption of roots and adjacent tooth were healthy. There is usually no pain or discomfort associated with dentigerous cyst unless there is acute inflammatory exacerbation. ${ }^{18}$

Panoramic and periapical radiographs are good at revealing displacement of the tooth buds and showing root resorption. Simple radiological investigation like $\mathrm{X}$-ray of paranasal sinuses is useful in confirming the diagnosis, visualizing any ectopic teeth and also to assess the extent of cyst. Computed tomography scan of paranasal sinus was not done as the patient could not afford it and the diagnosis was reliably made from the $\mathrm{X}$-ray findings itself.

Microscopic features of the cystic wall showed nonkeratinizing stratified squamous epithelium lined fibrous connective tissue. In case of maxillary cyst, it is pseudostratified columnar, simple columnar or cuboidal. ${ }^{3}$ Neopastic changes in the walls of long standing dentigerous cyst giving rise to squamous cell carcinoma and plexiform ameloblastoma are also reported. ${ }^{13,14}$ The treatment of dentigerous cyst includes intact surgical enucleation or marsupilization. ${ }^{15}$ The treatment of choice is dependent on the size and localization of the lesion, the bone integrity of the cystic wall and its proximity to vital structures. Cysts are usually enucleated, where the cystic lining is separated from its inner bony surface and removed and the cavity allowed filling with blood clot. ${ }^{16}$

We avoided the Weber Fergusson incision and preferred the Caldwell-Luc approach as the full extent of the cyst was approachable through the gingivobuccal sulcus. So, this approach is equally useful ${ }^{17}$ and gives cosmetically better results by avoiding any facial scar.

Other therapeutic approaches include endodontic treatment of the primary tooth and marsupialization of the lesion, aspiration and enucleation ${ }^{20}$ and transnasal endoscopic removal. Gondim et al reported that with proper case selection, marsupialization might be a good treatment option for conservative management of dentigerous cysts as it promotes involution and stimulated osteogenesis. ${ }^{20}$ This simplifies the surgical enucleation of the specimen and removal of the unerupted tooth without the excessive loss of the bony contours of the maxilla.

\section{CONCLUSION}

Dentigerous cyst is a developmental odontogenic cyst, which apparently develops by accumulation of fluid between the reduced enamel epithelium and the tooth crown. Although, dentigerous cysts of the maxillary sinus are most commonly associated with maxillary third molars, this study reports a case of ectopic supernumerary canine. Large dentigerous cysts cause massive expansion of the jaws and so, are its varied clinical presentations and complete nasal blockade is one of them. This case highlights the need for clinicians to be aware of the rarer causes of nasal obstruction and the importance of simple radiological investigation like the X-ray of paranasal sinuses. Moreover, the diagnosis of dentigerous cyst should not be ruled out clinically by just considering a normal dentition as supernumerary teeth can be a possibility. Treatment modality should depend on the size of the cyst, type of teeth involved and conditions of adjacent tooth. In cases of large dentigerous cysts requiring surgical removal, besides the usual Weber-Fergusson's incision, sublabial or Caldwell-Luc approach is equally useful and gives cosmetically better results.

\section{REFERENCES}

1. Kusukawa J, Iric K, Morimatsu M, Koynagi S, Kameyana T. Dentigerous cyst associated with a deciduous tooth. Oral Surg Oral Med Oral Pathol 1992;73:415-418.

2. Pathania V, Kirtaniya B, Mittal S, Sharma AK. Supernumeraries: the devils of the oral cavity, their clinical management in pediatric dentistry - a report of three cases with literature review. Int J Contemp Dent Med Rev 2015; Article ID: 270115: 2015.

3. Schafers WF, Hine ML, Levy BM. A textbook of oral pathology. 4th ed. Philadelphia: PA, Saunders; 1983;271-273.

4. Sharma Y, Kaushik S, Singh PP. A case of large dentigerous cyst containing canine tooth in the maxillary antrum. Ind J Otolaryngol Head Neck Surg 2000;51(3):66-68.

5. Yusof WZ. Non-syndrome multiple supernumerary teeth: literature review. J Can Dent Assoc 1990 Feb;56(2):147-149.

6. Rajab LD, Hamdan MA. Supernumerary teeth: review of the literature and a survey of 152 cases. Int J Paediatr Dent 2002;12(2):244-254.

7. Brook AH. Dental anomalies of number, form and size: their prevalence in British school children. J Int Assoc Dent Child 1974;5:37-53.

8. Ishikawa G. Oral Pathology. 2nd ed. Kyoto: Nagasue Shoten Co; 1982. p. 379-381. 
9. Frer AA, Friedman AL, Jarrett WJ, Brooklyn NY. Dentigerous cyst involving the maxillary sinus. Oral Surg 1972 Sep;34(3):378-380.

10. Most DS, Roy EP. A large dentigerous cyst associated with a supernumerary tooth. Am Assoc Oral Maxillofac Surg 1982;40(2):119-120.

11. Struthers PJ, Shear M. Root resorption produced by enlargement of ameloblastoma and cyst of the jaws. Int J Oral Surg 1976;5(3):128.

12. Atlas E, Karasen RM, Yilmaz AB, et al. A case of large dentigerous cyst containing canine tooth in the maxillary antrum leading to epiphora. J Laryngol Otology 1997;111(7):641-643.

13. Gardner DG. Plexiform unicystic ameloblastoma: a diagnostic problem in dentigerous cyst. Cancer 1981;47(6):1358.

14. Berenholz L, Gottleib RD, Cho YS, et al. Squamous cell carcinoma arising in dentigerous cyst. ENT J 1988;67(10):764.

15. Shenoy P, Paulose KO, Khalifa SA, Sharma RK. Odontogenic keratocyst involving the maxillary antrum. J Laryngol Otology 1988;102(12):1168-1171.

16. Kumar JA, Achuthan N, Loganathan K, Augustine D. Effective management of a large radicular cyst with surgical enucleation. Oral Maxillofac Pathol J 2014;5(1):459-461.
17. Kaya O, Bocutoglu O. A misdiagnosed giant dentigerous cyst involving the maxillary antrum and affecting the orbit: case report. Aust Dent J 1994;39(3):165-167.

18. Prabhu SP, Padwa BL, Robson CD, Rahbar R. Dentigerous cyst associated with a displaced tooth in the maxillary sinus: an unusual cause of recurrent sinusitis in an adolescent. Pediatr Radiol 2009 Oct;39(10):1102-1104

19. Khan $\mathrm{MH}$, Alam MT, Haque $\mathrm{S}, \mathrm{Khan} \mathrm{SH}$, Fatema $\mathrm{CN}$, Tahsin T, Choudhury AR. Upper lip swelling caused by a large dentigerous cyst with mesiodens. Mymensingh Med J 2008 Jul;17(2 Suppl):S100-103.

20. Gondim JO, Neto JJ, Nogueira RL, Giro EM. Conservative management of a dentigerous cyst secondary to primary tooth trauma. Dent Traumatol 2008 Dec;24(6):676-679.

21. Gibson GM, Pandolfi PJ, Luzader JO. Case report: a large radicular cyst involving the entire maxillary sinus. General Dentistry 2002;50(1):80-81.

22. Shun Y. Dentigerous cyst associated with an impacted anterior maxillary supernumerary tooth. J Dent Child (Chic) 2008 Jan-Apr;75(1):104-107. 